\title{
Esophageal Low Grade Intraepithelial Neoplasia
}

National Cancer Institute

\section{Source}

National Cancer Institute. Esophageal Low Grade Intraepithelial Neoplasia. NCI

Thesaurus. Code C4840.

A lesion in which the architectural and cytologic abnormalities are confined to the lower

half of the esophageal epithelium. (WHO, 2000) -- 2003 